\title{
Survey of Parasitologique Surface Water Quality (R'Dom Oued Sidi Kacem, Morocco)
}

\author{
Fatima Benel Harkati, Khadija Elkharrim, Sadek Sanae, Driss Belghyti
}

Laboratory of Environment and Renewable Energies, Faculty of Sciences, Ibn Tofaïl University, Kenitra, Morocco. Email: harkati_fatima@hotmail.fr,belghyti@hotmail.com

Received August $16^{\text {th }}, 2013$; revised September $18^{\text {th }}, 2013$; accepted October $17^{\text {th }}, 2013$

Copyright (C) 2013 Fatima Benel Harkati et al. This is an open access article distributed under the Creative Commons Attribution License, which permits unrestricted use, distribution, and reproduction in any medium, provided the original work is properly cited.

\begin{abstract}
Domestic effluent from the city of Sidi Kacem in the north-western Morocco is released untreated into the Oued R'dom. We propose in this study to proceed with sampling wastewater at the three collectors Oued R'dom from upstream (Bab tissra) to downstream (Zirara) through the domestic center of the city of Sidi Kacem. The sampling was carried out twice a month over a period of five months (January, February, March, April and May). We used the technique Bailenger amended by [1]. At the upstream percentages of positive samples helminth eggs found in wastewater are: Nematodes $30 \%, 20 \%$ and $10 \%$ Ascaris sp, Trichuris sp, Enterobius vermicularis for Cestodes $30 \%$ Taenia. Sp and the eggs and larvae of strongyles $30 \%$. At the home collector (C) nematodes are represented by the eggs of Ascaris sp, $60 \%$, followed by Tri-churis sp. $40 \%$ for Enterobius. Vermicularis eggs sp. représentent $20 \%$ of the class Cestoda with percentages of positive samples for Taenia sp 30\% and 10\% for Hymenolepis. sp. is isolated from cyst protozoan Entamoeba coli $10 \%$ for eggs, and larvae of strongyles $60 \%$ presented in the wastewater at the Downstream class nematodes is $70 \%$ with $40 \%$ of Ascaris sp, and $30 \%$ Trichuris sp. la class Cestoda is represented by $30 \%$ of Taenia. Sp. et Hymenolepis's. Sp. $10 \%$. For eggs and larvae of strongyles is $40 \%$. Exceeding the WHO standards, these parasites pose a potential hazard to the direct and indirect use of wastewater from the town of Sidi Kacem.
\end{abstract}

Keywords: Wastewater; Noise; Pollution; R'Dom Oued Sidi Kacem; Morocco

\section{Introduction}

The city of Sidi Kacem is particularly affected by the pollution problem, because of its growing population and ongoing development of the industrial and agricultural sector. The river is one of R'dom wadis superficial network of the city, currently threatened by human activities which often have a negative impact on the health of populations. Domestic wastewater contains all microorganisms excreted with faeces. This normal enteric flora is accompanied by pathogens. They are therefore of particular interest to specialists in public health because they reflect the level of infestation of human and animal populations as they arise $[1,2]$.

\section{Study Area}

Sidi Kacem is located $84 \mathrm{~km}$ east of the city of Kénitra, $82 \mathrm{~km}$ north-west of the city of Fez and $46 \mathrm{Km}$ north of the city of Meknes (Figure 1). According to the 2004 census, the population of Sidi Kacem was 74,062 inhabitants which covers a geographical area of 199.909 ha also an extensive network of wadis touring the province: Oued R'dom-Oued Ourgha-Oued Sebu. It is characterized by a continental climate semi-arid. Monthly rainfall $(393 \mathrm{~mm})$ and the dry season is between June and September. We are interested in three main sewers of the city (Figure 1).

- Collector A: It drains upstream of Wadi R'dom.

- Collector B: It drains downstream Oued R'dom.

- Collector C: It drains the center of the town of Sidi Kacem (domestic sewage).

\section{Method of Study}

Samples of wastewater 2 liters each are collected and preserved by the addition of $10 \%$ formalin $(2 \mathrm{ml} /$ liter $)$ in clean bottles and transported to the Laboratory of Environment and Renewable Energies. The wastewater samples were placed in test tubes 1 liter and allowed to settle for eight hours (overnight).

In this research, we opted for the WHO recommended to characterize the parasite load of wastewater Sidi Kacem 


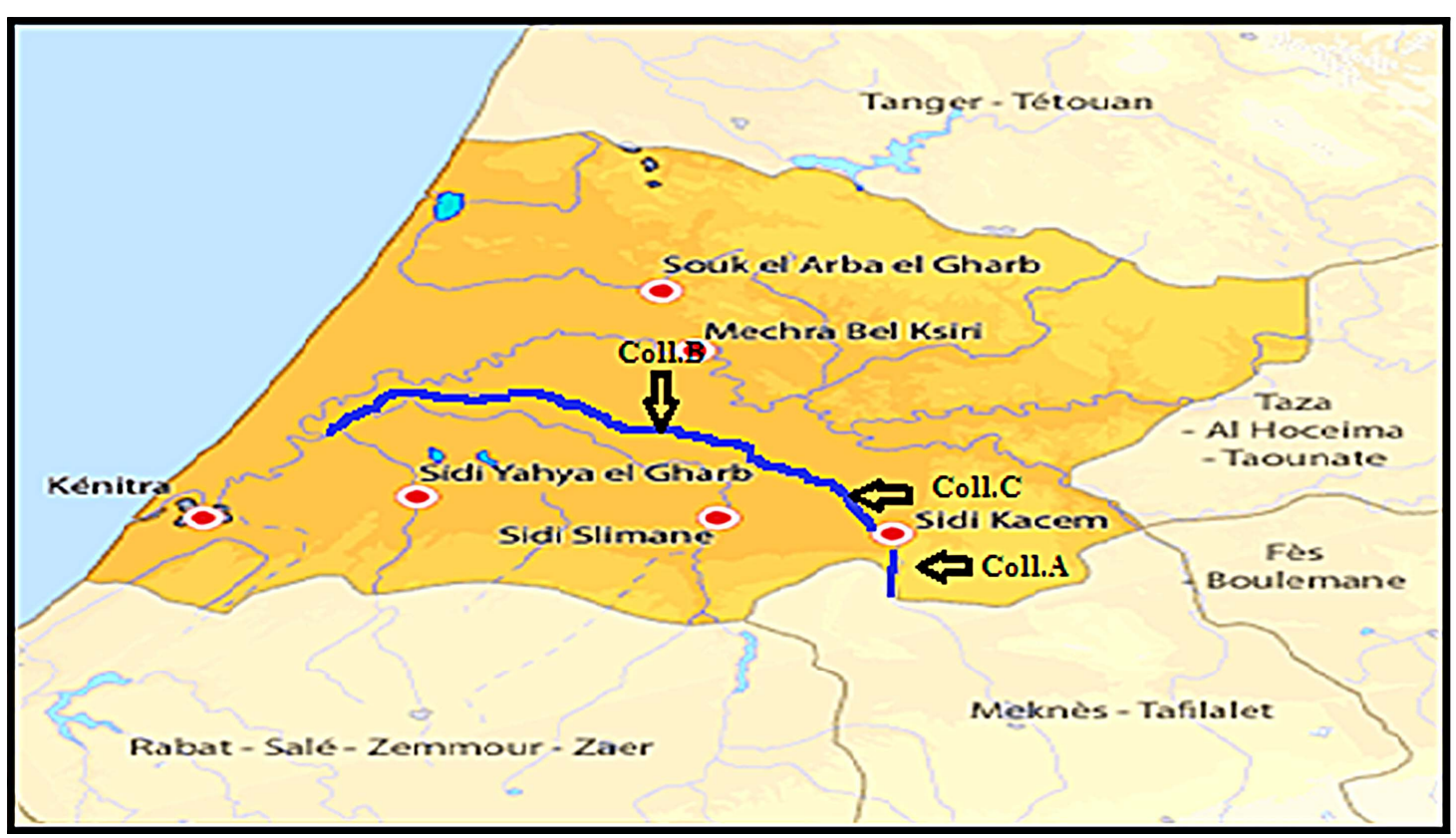

Figure 1. Location of Sidi Kacem and Location of sampling stations Oued R'dom [13].

technique [3]. It is interesting for its speed, simplicity, efficiency and reproducibility. This method is intended for the concentration of parasitic elements, the identification of helminth eggs was carried out at a magnification of $x$ 1000.

\section{Results}

The analysis of wastewater from the urban center of Sidi Kacem reflects parasite diversity: the helminth parasites and eggs and larvae of strongyles and a difference in quantitative and qualitative terms (Figure 2). For our present study, monitoring of wastewater main sewers of the city shows that they are contaminated with the eggs of helminths which are distributed between two classes, nematodes and cestodes with the predominance of the first class. This has also been highlighted by [4]. This predominance of eggs class nematodes was related primarily to lifestyle of the population in question whose eating habits (consumption cooked meat) do not support the transmission of tapeworms [5]. By Moreover [6-8] reported the eggs of intestinal nematodes are more resistant than those of Cestoda in wastewater. This dominance has been reported by several authors in Morocco [9-11].

Analytical results based on sample collectors studied showed that the collector C (domestic sewage effluent), the waters are more contaminated with helminth eggs, larvae of strongyles over manifolds A and B (Upstream and Downstream) (Figure 2). This difference in charge of helminth eggs can be explained by the demographic profile of the urban population connected to the sewage collectors. According [2], the concentration of helminth eggs in urban wastewater is strongly related to demographic fac-

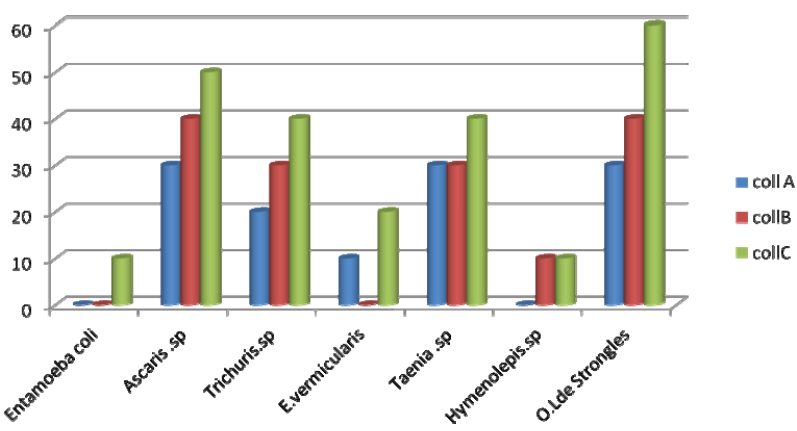

Figure 2. Representation of helminth eggs found in wastewater the town of Sidi Kacem.

tors and is responsible for the increase in the concentration of helminth eggs in wastewater.

Differences in socio-economic influenced the parasitic load wastewater. This was also reported in many studies worldwide, because all sewage collectors parasite load underwent monthly fluctuations. Indeed, the diversity of parasites encountered varied from one station to another and from one month to another, as a function of, originally, the location of the station and the type of wastewater and depending on the climatic conditions of the region.

The percentages of positive samples recorded in the wastewater as well as those of work mentioned above greatly exceed the standards recommended by WHO [12] and the CNS of the Ministry of Environment of Morocco (1 viable nematode egg per liter) for water for crop irrigation. According to $\mathrm{WHO}$, the presence of intestinal nematodes, mainly Ascaris sp. Trichuris E. vermicularis and Entamoeba coli in wastewater is considered as a major 

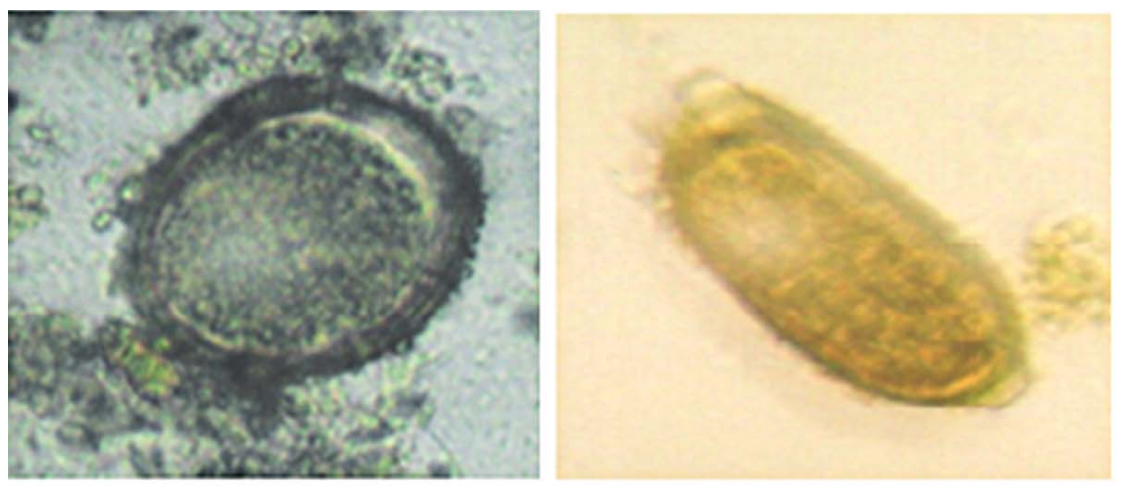

Fuf d'ascaris $s p(x 40)$
Eufs de Trichuris sp. $(x 40)$

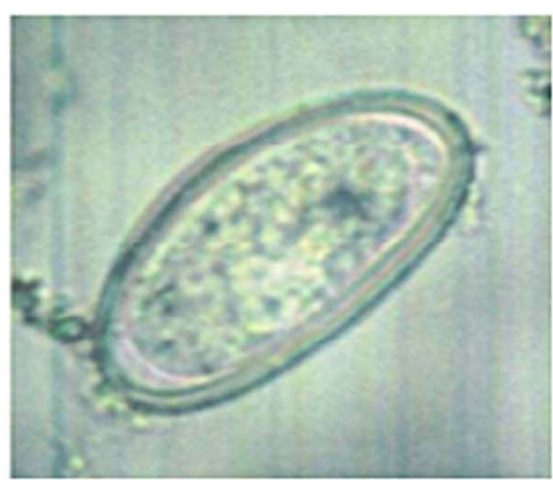

CFuf d'Enterobius vermicularis $(x 40)$

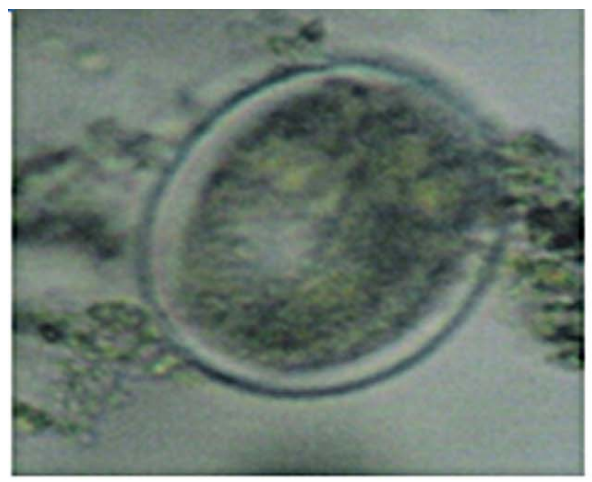

Fuf de strongle(x40)

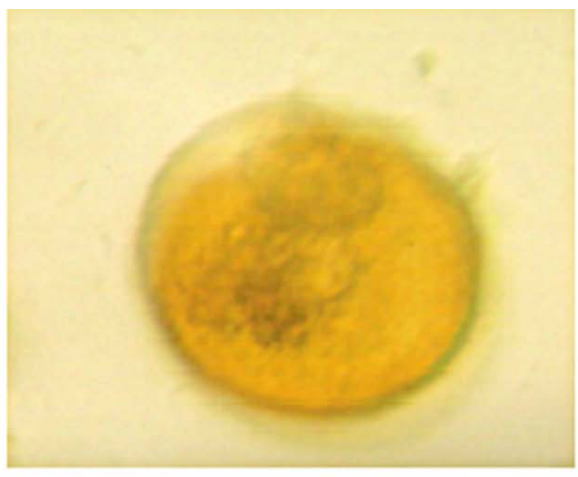

Kyste d'Entamoeba coli( $(40)$

Figure 3. Illustration of parasite species wastewater (performed at the Faculty of Sciences of Kenitra).

risk for the reuse of water in agriculture (Figure 3).

At the end of our study on the analysis of wastewater Sidi Kacem, we reached the following conclusions: There is a qualitative difference in the parasite load of the waters studied, the water drained by the collector $\mathrm{C}$ (domestic) are loaded parasitic elements as collectors A and B.

The qualitative and quantitative characterization of parasites in wastewater from the town of Sidi Kacem (for collectors A, B and C) (Figure 3) is a parameter to take into account in assessing the parasitological quality of raw sewage to optimize an average treatment. Furthermore, the concentration of helminth eggs in wastewater is exceptionally sensitive to the size and demographic structure of population connected to sewerage network [11]. Moreover, the assessment of water quality of the river gives a true picture of the pollution of the environment aims. Wastewater loaded parasitic elements are also a natural hazard for surface water when released in the rough To eliminate the environmental and health hazards caused by the discharge of wastewater to crude in receiving waters (Oued R'dom, groundwater) it is essential installing a water treatment plant that will treat wastewater and reconsider wastewater as a water resource to be mobilized and valued in the same way as conventional water.

\section{REFERENCES}

[1] WHO, "The Use of Wastewater in Agriculture and Aquaculture Recommendations Health Report Referred to a Group of WHO Experts," Series of Reports Techniques, WHO, Geneva, 1986.

[2] K. Bouhoum, O. Amahmid, Kh. Habbari and D. Schwartzbrod, "Become Helminth Eggs and Protozoan Cysts in Open Channel Fed by Wastewater from Marrakech," Review Science Water, Vol. 2, 1997, pp. 217-232.

[3] J. Bailenger, "Mechanisms of Parasitological Concentration in Coprology and Their Parasitical Consequences," American Journal of Medical Technology, Vol. 41, 1979, pp. 65-71.

[4] N. Naur, "Impact of Wastewater Reuse in Agriculture Contamination Cultures by Helminth Eggs," 3rd Cycle Thesis, Cadi Ayyad University, Fac. Sci. Marrakech, 1996, $101 \mathrm{p}$.

[5] J. Bontoux, "Introduction to the Study of Fresh Waters, Surface Waters, Wastewater, Drink, Part IV," The Tribune Cebedeau, Liège, Vol. 36, 1983, pp. 381-398.

[6] Z. Alouini, H. Achour and A. Alouini, "Becoming the Pa- 
rasite Load of Wastewater Addressed in the 'Cebala' Irrigation Network," In: L. A. Zekri, Ed., Agriculture and Sustainability Environment, Zaragoza, CIHEAM, 1995, pp. 117-124.

[7] M. Guessab, J. Bize, J. Schwartzbrod, A. Mani, M. Morlot, N. Nivault and L. Schwartzbrod, "Wastewater Treatment Dry Infiltration Percolation on Sand: Sergao Results in Ben. Morocco," Water Science Technology, Vol. 17, 1993, pp. 91-95.

[8] J. Schwartzbrod and S. Banas, "Parasite Contamination of Liquid Sludge from Urban Wastewater Treatment Plants," Water Science Technology, Vol. 47, No. 3, 2003, pp. 163166.

[9] K. H. Habbari, "Impact of the Use of Wastewater on the Epidemiology of Helminth Infections and Growth in Children of El Azouzia," 3rd Cycle, Fac. Sci. Marrakech, 1992.
[10] C. L. Nsom Zamo-A. and D. M. Belghyti Lyagoubi, "Parasitological Study of Helminths Eggs Carried by the Untreated Wastewater Maâmora of the Urban District (Kenitra-Morocco)," European Journal of Hydrology, Vol. 34, No. 2, 2003, pp. 245-250.

[11] Y. El Guamri and D. Belghyti, "Parasite Load of Raw Sewage from the City of Kenitra (Morocco)," Africa Science, Vol. 3, No. 1, 2007, pp. 123-145.

[12] U. J. Blumenthal, D. Duncan Mara, A. Peasey, G. RuizPalacios and R. Stott, "Guidelines for the Microbiological Quality of Treated Wastewater Used Inagriculture: Recommendations for Revising," WHO Guidelines, Bull of the World Health Organization, Vol. 78, No. 9, 2000, pp. 1104-1116.

[13] ONEP, "Study of Sanitation in the City of Sidi Yahia Gharb before Project Summary," 2005, 138 p. 